\title{
EDUCAÇÃo POPULAR: UMA EXPERIÊNCIA DE FORMAÇÃo CONTINUADA DE PROFESSORES NA EdUCAÇÃo de Jovens e Adultos (EJA) No PROJETO SAL DA TERRA
}

\author{
POPULAR EDUCATION: AN EXPERIENCE OF CONTINUING TEACHER EDUCATION IN YOUTH \\ AND ADULT EDUCATION (EJA) IN SAL DA TERRA PROJECT
}

EDUCACIÓN POPULAR: UNA EXPERIENCIA DE FORMACIÓN CONTINUA DEL PROFESORADO EN EDUCACIÓN DE JÓVENES Y ADULTOS (EJA) EN EL PROYECTO SAL DA TERRA

\section{Jeane Tranquelino da Silva (iD)}

Doutoranda em Educação, mestre em Educação, Pedagoga

Membro do Grupo de Estudos e

Pesquisas em Educação Popular, Serviço Social e Movimentos Sociais (GEPEDUPSS) e do Grupo de Estudos e Pesquisas Educação, Etnias e Economia Solidária (GEPEEES) da Universidade Federal da Paraíba (UFPB) jeanemestrelopes@gmail.com

\section{Aline Maria Batista Machado (iD) 9}

Doutora em Educação, mestre em Serviço Social e assistente social Docente do PPGE e PPGSS da UFPB e coordenadora do Grupo de Estudos e Pesquisas em Educação Popular, Serviço Social e Movimentos Sociais (GEPEDUPSS) prof.alinemachado23@yahoo.com

\begin{abstract}
Resumo
O presente artigo constitui um recorte de pesquisa de mestrado no Programa de Pós-Graduação em Educação da Universidade Federal da Paraíba. Seu objetivo foi analisar o processo de formação continuada dos professores da EJA no Projeto Sal da Terra e identificar os princípios da Educação Popular. A pesquisa possui uma abordagem qualitativa do tipo estudo de caso. Para a coleta de dados, foram realizadas entrevistas semiestruturada, análise documental e observação participante. Os dados foram analisados com base na técnica de Análise de Conteúdo, preconizada por Bardin (2011). A partir dos relatos dos professores, constatou-se as contribuições dos princípios "diálogo", "participação" e "cidadania" da Educação Popular, desenvolvidos na formação que contribuem efetivamente na formação continuada das educadoras, porém, categorias como "conscientização" e "práxis" não se fizeram presentes, revelando que o Sal da Terra é relevante, mas não apresenta uma educação efetivamente emancipadora, visto que os entrevistados apresentaram limitações no que diz respeito aos princípios constituintes da Educação Popular.
\end{abstract}

Palavras-chave: Formação de Professores. Projeto Sal da Terra. Formação Continuada.

Recebido em: 1 de abril de 2021.

Aprovado em: 18 de agosto de 2021.

Como citar esse artigo (ABNT):

SILVA, Jeane Tranquelino da; MACHADO, Aline Maria Batista. Educação Popular: uma experiência de formação continuada de professores na Educação de Jovens e Adultos (EJA) no Projeto Sal da Terra. Revista Prática Docente, v. 6, n. 2, e059, 2021.

http://doi.org/10.23926/RPD.2021.v6.n2.e059.id1071 


\begin{abstract}
This article is an excerpt from an exploratory research carried out at the master's level in the Post-Graduate Program in Education at the Federal University of Paraíba. The objective of the research was to analyze the process of continuing education developed by the Sal da Terra Project in João Pessoa-PB with the teachers of the EJA modality, and to identify the principles of Popular Education. As this is a case study and empirical and documentary research, with a qualitative approach, we resort to the dialectical method for a more critical analysis. As procedures for data collection, we conducted a semi-structured interview with educators and with the project's pedagogical coordination, document collection and participant observation. The collected data were worked based on the Content Analysis technique, recommended by Bardin (2011). From the teachers' reports, we found contributions from the principles of "dialogue", "participation" and "citizenship" of Popular Education, which were developed in the training provided by the project to EJA teachers, however, categories such as "awareness" and "praxis" were not present, revealing that the project is relevant, but it does not present a high emancipatory education, since the interviewees had limitations with respect to the main constituents of Popular Education.
\end{abstract}

Keywords: Teacher Education. Sal da Terra Project. Continuing Education.

\title{
Resumen
}

Este artículo es un extracto de una investigación exploratoria realizada a nivel de maestría en el Programa de Posgrado en Educación de la Universidad Federal de Paraíba. El objetivo de la investigación ha sido analizar el proceso de educación continua desarrollado por el Proyecto Sal da Terra en João Pessoa-PB con los docentes de la modalidad EJA, e identificar los principios de la Educación Popular. Al tratarse de un estudio de caso e investigación empírica y documental, con un enfoque cualitativo, recurrimos al método dialéctico para un análisis más crítico. Como procedimientos de recolección de datos, realizamos una entrevista semiestructurada con educadoras y con la coordinación pedagógica del proyecto, búsqueda de documentos y observación participante. Los datos recolectados han sido trabajados con base en la técnica de Análisis de Contenido, recomendada por Bardin (2011). Desde los informes de los docentes, hemos constatado los aportes de los principios de "diálogo", "participación" y "ciudadanía" de la Educación Popular, los cuales han sido desarrollado en la formación que ofrece el proyecto a los docentes de EJA, sin embargo, categorías como " conciencia" y "praxis" no estuvieron presentes, revelando que el proyecto es relevante, pero no presenta una educación efectivamente emancipadora, ya que los entrevistados tenían limitaciones con respecto a los principales constituyentes de la Educación Popular.

Palabras clave: Formación del professorado. Proyecto Sal da Terra. Educación continua. 


\section{INTRODUÇÃ̃O}

O presente artigo é um recorte de uma pesquisa em nível de mestrado em Educação realizado na Universidade Federal da Paraíba - UFPB, cujo objetivo central foi analisar o processo de formação continuada desenvolvido pelo Projeto Sal da Terra no município de João Pessoa, na Paraíba, com os professores da modalidade da Educação de Jovens e Adultos (EJA), e identificar os princípios da Educação Popular, tais como "diálogo", "conscientização" e "participação", eventualmente presentes no processo formativo.

Inicialmente, pensávamos que esse o Projeto Sal da Terra era uma ONG (Organização Não-Governamental). No decorrer da pesquisa, os coordenadores deixaram claro que não se tratava de uma ONG, mas sim de um projeto. Por isso, o lócus da pesquisa aqui apresentada é o próprio projeto de alfabetização de jovens e adultos, denominado Projeto Sal da Terra, que nasceu em 1989 com um grupo de freiras da Congregação do Sagrado Coração de Jesus, da comunidade Católica pertencente à Arquidiocese da Paraíba. O Projeto Sal da Terra tem como objetivo promover o conhecimento da leitura, da escrita e da matemática para as pessoas que não eram alfabetizadas das comunidades do município de João Pessoa - PB. As raízes inspiradoras dessa experiência estão na teologia do povo de Deus do Concílio Vaticano II e na teologia da Igreja dos pobres, motivadas por Medellín e Puebla, expressas na Teologia da Libertação e traduzidas nas práticas das Comunidades Eclesiais de Base (CEBs) dos anos de 1970. Na tentativa de dar respostas às necessidades educacionais das comunidades, tendo em vista o alto número de pessoas analfabetas, foram criadas turmas de alfabetização para jovens e adultos em vários municípios da Paraíba.

Historicamente o Brasil viveu durante muitos anos o desafio do analfabetismo, neste sentido, a Constituição Federal de 1988 representou uma importante conquista no campo da educação brasileira, reconhecendo a educação como um direito assegurado a todo cidadão, e definindo explicitamente a quem confere essa obrigação, conforme expressa o art. $205^{\circ}$ da referida Constituição: A Educação é direito de todos e dever do Estado e da família, será promovida e incentivada com a colaboração da sociedade, visando ao pleno desenvolvimento da pessoa, seu preparo para o exercício da cidadania e sua qualificação para o trabalho (BRASIL, 1988, p. 121).

Diante das conquistas legais referendadas pela Constituição de 1988 para o campo da educação, destacam-se os instrumentos jurídicos que vêm respaldando a política de formação de professores no Brasil, a exemplo do que consta no art. $206^{\circ}$ da Constituição, inciso V, que 
versa sobre a valorização dos profissionais da educação. Esse princípio foi contemplado na Lei de Diretrizes e Base da Educação Nacional (LDBEN) n 9.394/96, mais precisamente no Título VI, intitulado "Dos Profissionais da Educação", abrangendo os artigos $61^{\circ}$ ao $67^{\circ}$. Nesse contexto, o art. $62^{\circ}$, que aborda a formação docente, prevê que:

\begin{abstract}
A formação de docentes para atuar na educação básica far-se-á em nível superior, em curso de licenciatura, de graduação plena, em universidades e institutos superiores de educação, admitida, como formação mínima para o exercício do magistério na educação infantil e nas quatro primeiras séries do ensino fundamental, a oferecida em nível médio, na modalidade Normal (BRASIL, 1996).
\end{abstract}

Nesse sentido, a formação dos professores da educação básica deve ser realizada em nível superior, sendo a universidade o lócus privilegiado para essa formação (seja inicial ou continuada), pois, conforme Souza (2007) e Scheibe (2006), constitui espaço próprio da realização da tríade: ensino, pesquisa e extensão.

A formação do professor constitui base singular na qualidade da ação profissional, tornando-se, portanto, o eixo central na construção dos futuros profissionais da educação. Em face às diversas mudanças ocorridas na trajetória histórica e cultural que culminaram na consolidação das bases educativas hoje existentes, os professores têm o desafio de articular teoria e prática no exercício da docência dentro e diante dos conflitos históricos da sociedade.

\title{
2 REFERENCIAL TEÓRICO
}

Historicamente, no Brasil e na América Latina, o campo da Educação Popular ganhou força em contextos de "governos autoritários que reprimiam formas libertárias de educação" (BRANDÃO, 1994, apud SILVA, 2016, p. 49), vetando qualquer forma de educação que buscasse um processo de conscientização. A Educação Popular é parte de um processo histórico compreendido a partir do encontro de forças antagônicas em constante conflito, marcado por avanços e contradições. Ao longo de sua trajetória, apresenta-se como instrumento de organização das classes populares e de construção de metodologias que fortalecem as ações dos diversos movimentos sociais. De acordo com Brandão (2012, p. 101): Educação popular é, em si mesma, um movimento de trabalho pedagógico que se dirige ao povo como um instrumento de conscientização [..], realiza-se como um trabalho pedagógico de convergência entre professores e movimentos populares

Por conseguinte, Educação Popular é um paradigma educacional contra hegemônico, que visa contribuir com a construção de um projeto de sociedade alicerçado em princípios éticos 
de solidariedade, justiça e igualdade, em que a população, perversamente excluída do sistema capitalista, possa ter plenos direitos e garantias constitucionais.

No contexto brasileiro, a Educação Popular emergiu entre fins dos anos de 1950 e início dos anos de 1960, a partir de "um movimento de expressão popular em cujo interior se inscreveram as mais diversas iniciativas de cunho educativo" (BEZERRA, 1984, apud MACHADO, 2012, p. 156). Conforme informa a autora, dentre as mais diversas expressões de movimentos populares destacaram-se, nesse cenário do início dos anos de 1960, as novas formas de mobilizações dedicadas à Educação de Jovens e Adultos, protagonizadas por setores da sociedade civil organizada: Movimento de Cultura Popular (MCP), em Recife; Campanha de Pé no Chão também se Aprende a Ler, em Natal; Campanha de Educação Popular da Paraíba (CEPLAR), na Paraíba; Centro Cultural da UNE e Movimento de Educação de Base (MEB), este último criado pela Igreja Católica. Esses movimentos fomentaram o surgimento do paradigma da Educação Popular que se deu por meio de ênfases diferentes de acordo com as ideologias de grupos políticos, sociais e eclesiais.

Nessa direção, concordamos com o pensamento de Paulo Freire sobre a Educação Popular, que a compreende como: "um esforço no sentido da mobilização e de organização das classes populares com vistas à criação de um poder popular” (FREIRE, 2002, p. 74). E acrescenta:

Como um paradigma educacional, cuja metodologia visa atuar com o povo e nunca para o povo; como uma educação que parte dos níveis de percepção em que se encontram os educandos, os grupos populares, e com eles ir avançando e transformando em rigor científico.

Nessa perspectiva, o ser humano é compreendido como um sujeito de múltiplas relações no mundo e com o mundo: "daí sua ação não poder incidir sobre as partes isoladas, pensando que assim transforma a realidade, mas sobre a totalidade” (FREIRE, 1999, p. 21).

Enquanto uma das grandes referências da Educação Popular, o referido autor também destaca que, no que se refere à formação de professores, é necessário que o educador conheça o contorno geográfico, social e econômico dos educandos. E complementa: "A formação dos professores e das professoras devia insistir na constituição deste saber necessário (...) que é a importância inegável que tem sobre nós o contorno ecológico, social e econômico em que vivemos" (FREIRE, 2005, p. 117). 


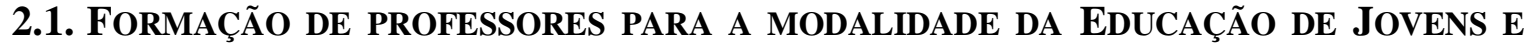

\section{Adultos}

A Educação de Jovens e Adultos (EJA) começou a delimitar o seu lugar na história da educação brasileira a partir da década de 1940, quando, finalmente, começou a se consolidar como um sistema público de educação elementar. Analisando o campo da EJA no tocante à formação de professores, constatamos que ela sempre foi negligenciada e tratada com ações pontuais, fragmentadas e desconectadas das políticas públicas. Nos últimos anoessa modalidade de educação conquistou importantes avanços no campo das políticas educacionais, frutos das várias discussões e lutas travadas por diversos movimentos sociais para que a Educação de Jovens e Adultos se tornasse uma política pública gratuita culminaram na promulgação da Lei de Diretrizes e Bases da Educação Nacional (LDB 9.694/1996). Existe uma ernorme lacuna no tocante à política de formação de professores para a Educação de Jovens e Adultos. Embora algumas conquistas nesse campo tenham sido alcançadas com a LDB, visto que essa lei garante direitos e estabelece diretrizes sobre a formação docente, uma política pública satisfatória na áerea ainda não foi suprida.

A formação de profissionais da educação, de modo a atender aos objetivos dos diferentes níveis e modalidades de ensino e as características de cada fase do desenvolvimento do educando, terá como fundamentos:

I - associação entre teorias e práticas, inclusive mediante a capacitação em serviço;

II - aproveitamento da formação e experiências anteriores em instituições de ensino e outras atividades (BRASIL, 1996).

Nesse sentido, pensar a formação de professores na Educação de Jovens e Adultos é um desafio que precisa ser superado. O professor da EJA com formação em nível de licenciatura, para atuar na educação básica e nos espaços da educação superior, necessita de uma formação específica que ofereça suporte para o exercício da docência em sala de aula. A formação inicial tem a finalidade de construir as bases necessárias de conhecimentos e habilidades para que esses profissionais da educação possam exercer suas atividades com competência e propiciar a aprendizagem aos seus alunos.

A esse respeito, Tardif (2000, p.115) afirma que: “O professor é um sujeito que assume sua prática a partir dos significados que ele mesmo lhe dá, um sujeito que possui conhecimentos e um saber-fazer provenientes de sua própria atividade e a partir dos quais ele a estrutura e a orienta". Essa concepção nos provoca sobre a formação docente, tanto para a compreensão da influência da história de vida na constituição do professor (de sua prática pedagógica) como 
para um maior reconhecimento, por parte da academia, dos saberes docentes, num diálogo contínuo e formativo com aqueles que fazem a educação no chão das escolas.

Portanto, a formação dos professores, seja inicial ou continuada, é crucial na ação desses profissionais. É preciso pensar não apenas na formação inicial, mas também que tipo de formação continuada deve ser oferecida aos professores da EJA. Não é possível pensar na formação do professor no singular, como única, genérica e com um currículo aplicável em qualquer contexto.

A formação continuada para professores deve ser tomada como um dos pilares da escola de qualidade, espaço de reflexão crítica sobre a prática e formação integral do ser humano. Imbernón (2010) ressalta a formação continuada como fomento de desenvolvimento pessoal, profissional e institucional dos professores, elevando seu trabalho para transformação de uma prática.

A formação, na perspectiva da Educação Popular, visa contribuir com o processo de conscientização e mobilização das classes subalternizadas, a partir de uma teoria referenciada na realidade, na valorização dos saberes populares e de uma base ética e política voltada para a transformação social. Além disso, aposta em metodologias dialógicas que estimulam a luta coletiva pela emancipação humana.

Ao longo de sua trajetória, Paulo Freire explicou que, no geral, a Educação Popular se volta para uma pedagogia do oprimido, da autonomia, da indignação e do questionamento, exigindo: 1) respeito aos saberes populares dos educandos; 2) criticidade; 3 ) ética; 4) rejeição a qualquer forma de discriminação; 5) reflexão crítica sobre a prática; 6) corporeificação das palavras pelo exemplo; 7) reconhecimento e assunção da identidade cultural; 8) disponibilidade para o diálogo; 9) curiosidade; 10) competência profissional e generosidade; 11) consciência do inacabamento; dentre outras ações apontadas na obra Pedagogia da Autonomia (1999).

Em nossa pesquisa, evidenciamos o processo formativo do Projeto Sal da Terra realizado com professoras da modalidade da Educação de Jovens e Adultos que apresentaremos a seguir.

\section{Procedimentos do MÉtodo}

Nossa pesquisa caracteriza-se como um estudo de caso, de abordagem qualitativa, uma vez que visa à descoberta, enfatiza a interpretação em contexto, busca retratar a realidade de forma completa e profunda, e procura representar os diferentes e, às vezes, conflitantes pontos de vista presentes em uma situação social (LÜDKE; ANDRÉ, 2005). Esse tipo de abordagem 
parte do fundamento de que há uma relação dinâmica entre os sujeitos envolvidos e esse movimento possibilita que os conhecimentos sejam refletidos nas suas várias dimensões, considerando os diversos ângulos das observações sobre nossa investigação acerca do processo formativo desenvolvido pelo Projeto Sal da Terra.

Com relação à natureza desse tipo de pesquisa, Bogdan e Biklen (1994 p. 49) ressaltam que "a abordagem da investigação qualitativa exige que o mundo seja examinado com a ideia de que nada é trivial, que tudo tem potencial para constituir uma pista que nos permita estabelecer uma compreensão mais esclarecedora do nosso objeto de estudo".

Como procedimento, buscamos o apoio na análise documental, e como técnicas de coleta de informações, utilizamos a entrevista semiestruturada e a observação participante. Para o tratamento dos dados, optamos pela técnica de Análise de Conteúdo. A esse respeito, Bardin (2011) afirma que a sutileza dos métodos da análise de conteúdo colabora para a superação da incerteza das primeiras leituras. Nesse sentido, mediante a análise, de maneira coerente e sistemática, foram examinados os objetivos propostos na pesquisa que dizem respeito ao processo de formação dos professores que atuam na modalidade da Educação de Jovens e Adultos no Projeto Sal da Terra.

Os sujeitos da pesquisa foram 04 coordenadoras prestadoras de serviço, todas mulheres, entre 44 e 63 anos, com formação superior concluída ou em andamento em Pedagogia. O tempo de experiência das educadoras no projeto varia entre 1 e 4 anos. As entrevistas semiestruturadas foram realizadas no segundo semestre de 2016. Durante a pesquisa, recorremos aos documentos do projeto, tais como: relatório das educadoras, Projeto Político Pedagógico (PPP) do Sal da Terra, e entrevistas realizadas com as educadoras e a coordenação que foram fontes importantes de análise.

Para compreendermos se o Projeto Sal da Terra atua de fato com Educação Popular, fazse necessário uma breve reflexão sobre a Educação Popular e a formação de professores para a modalidade da EJA.

\section{Resultados E DisCuSSÕES DA PESQUISA}

\subsection{Projeto Sal da Terra: O Processo formativo e suas implicaÇões na PRÁtica DOCENTE}

O Projeto Sal da Terra está sediado no prédio do Sindicato dos Trabalhadores da Construção Civil no município de João Pessoa no estado da Paraíba (SINTRICON/PB) e 
funciona numa sala alugada. No local ocorre a formação pedagógica dos professores em momentos individuais e coletivos, em 11 salas de aula, que variam conforme os recursos disponíveis do projeto oriundos das parcerias estabelecidas a cada ano. As turmas funcionam em várias comunidades periféricas da cidade de João Pessoa e municípios circunvizinhos.

As ações desenvolvidas pelo projeto se configuram em dois campos de atuação: alfabetização e formação do educador. O trabalho de alfabetização dos jovens e adultos e a formação dos professores acontecem de forma sistemática, sendo acompanhados de quatro maneiras: a) individualmente, nos momentos de atendimento semanal que acontecem na sede do projeto; b) coletivamente, nos encontros e oficinas quinzenais, aos sábados; c) visitas pedagógicas; d) sistematização da prática pedagógica através de relatórios diários, semanais e quinzenais entregues à coordenação do projeto.

A formação individual dos professores é o momento em que a coordenação pedagógica acompanha de forma mais direta o resultado do trabalho em sala de aula de cada educador. A formação coletiva consiste em encontros quinzenais que acontecem no primeiro e no terceiro sábado de cada mês. No primeiro sábado, o trabalho é realizado em dois turnos e consiste na execução de oficinas com conteúdos temáticos de linguagem, matemática e estudos sociais e da natureza. As visitas pedagógicas constituem outro momento da formação, sendo desenvolvidas a partir do acompanhamento do educador em sua sala de aula. A sistematização da prática pedagógica complementa o conjunto dos elementos constituintes do processo formativo, em que o educador é orientado a registrar a sua prática pedagógica desde o momento em que planeja até a execução e avaliação.

Durante os encontros, a formação se configura como uma das principais atividades do Projeto Sal da Terra por se entender que, a partir dela, o educador pode compreender os saberes necessários à docência e considerar a prática pedagógica como objeto de sua reflexão. Essa sistemática de formação desenvolvida pelo projeto contribuiu efetivamente e significativamente no exercício da prática docente em salas da EJA.

Os depoimentos dos professores entrevistados revelaram algumas contribuições do processo formativo desenvolvido pelo projeto, como a presença de alguns princípios freirianos em suas ações:

Eu vejo no Projeto Sal da Terra a presença da educação popular na questão da Leitura de mundo, sempre buscando fazer a leitura do contexto em que os educadores estão inseridos, fazer a leitura dele para, depois, pensar formas de intervenção. Essa prática pedagógica contribui para a promoção humana (Educadora 4). 
A coordenação sempre considera nossos saberes e nos incentiva a superar nossas limitações; além disso, o diálogo é a base fundamental em todo processo do projeto. Aqui a gente tem vez e voz, não é só a coordenação que dita as coisas (Educadora 5).

Então, a educação popular está presente na prática pedagógica do projeto porque busca desenvolver nos sujeitos a criticidade, incentiva a participação na comunidade, associação e sindicatos visando à melhoria da qualidade de vida das pessoas (Educadora 7).

Percebemos, nas falas acima, um consenso em relação à presença de alguns constituintes da Educação Popular no processo formativo do projeto. No relato das educadoras, notamos a presença do diálogo, da criticidade, da participação e da leitura de mundo. Contudo, conforme os dados analisados, sentimos a ausência de outras categorias relevantes, a exemplo das categorias "práxis" e "conscientização". Desse modo, reportamo-nos à categoria "diálogo" como princípio que permeia a relação entre educador e educando: "O educador já não é o que apenas educa, mas o que, enquanto educa, é educado, em diálogo com o educando que, ao ser educado, também educa. Ambos, assim, se tornam sujeitos do processo" (FREIRE, 1987, p. 68).

$\mathrm{Na}$ contemporaneidade, cada vez mais torna-se pertinente discutir a formação do professor da EJA, visto que a formação inicial é uma etapa importante no processo formativo dos professores. A partir dela, é possível discutir sobre saberes necessários à prática docente. A formação desenvolvida pelo Projeto Sal da Terra tem sido imprescindível para essas professoras da EJA desenvolverem práticas pedagógicas que relacionem o cotidiano na sala de aula. $\mathrm{O}$ contato com as colegas e os alunos por meio da troca de experiências tem fortalecido o processo formativo, como constatamos nos depoimentos a seguir.

Através da formação a gente consegue melhorar nosso desempenho em sala de aula, porque aprendemos a trabalhar com a realidade do aluno e suas necessidades (Educadora 2).

Essa formação é muito rica, temos um grupo de educadoras, colegas, que partilham conosco seus conhecimentos e respeitam os nossos! Uma coordenação que a gente recebe todas as informações para exercer em nossa prática pedagógica. Aí a gente prepara nossa rotina referente a duas semanas (Educadora 5).

A partir dos depoimentos das professoras evidenciamos que na formação desenvolvida pelo Projeto Sal da Terra existe respeito e valorização dos conhecimentos trazidos pelos professores e, assim, eles aprendem na prática que esse respeito ao saber do educando se configura como um dos princípios da Educação Popular.

Ainda sobre a formação oferecida a esses professores, verifica-se uma significativa contribuição em suas práticas pedagógicas, conforme pode-se notar na fala do entrevistado abaixo: 
A experiência da formação quinzenal me ajudou muito na área de alfabetização de jovens e adultos. Sou professora da EJA com muito orgulho e o Projeto tem me ensinado cada dia mais. Na minha vida tenho aprendido que não há idade para aprender, nem ensinar, todos os dias estamos em aprendizado com meus alunos, vivemos uma troca de saberes (Educadora 6).

Os encontros de formação quinzenal têm contribuído para um repensar das ações desenvolvidas pelas educadoras, possibilitando uma ação reflexiva sobre a prática pedagógica e, ainda, colaborando para a reelaboração de novas estratégias pedagógicas. Essa experiência de formação continuada do Projeto Sal da Terra junto às educadoras tem contribuído para que elas possam desenvolver atividades pedagógicas significativas, relacionando os conteúdos curriculares às vivências e saberes dos alunos, buscando contemplar as necessidades dos sujeitos da EJA.

\section{CONSIDERAÇÕES FINAIS}

À guisa de considerações finais, podemos dizer que as professoras da EJA constroem saberes em diversos espaços e de formas diversas. Tais saberes são construídos, sobretudo, no contato com as colegas, nos momentos de formação realizados quinzenalmente pelo projeto, nas conversas com a coordenação e nos relatórios sistemáticos das atividades pedagógicas realizadas em sala de aula que são importantes instrumentos de avaliação da prática.

Ressalta-se que nos encontros formativos são contemplados temas e discussões que contribuem efetivamente no processo de aquisição de novos conhecimentos. Nesse sentido, as professoras da EJA reconhecem esses encontros como momentos importantes na sua formação, considerando que muitas metodologias e conhecimentos socializados não são encontrados nos livros, nem nas formações inicial ou continuada. São conhecimentos e saberes adquiridos por meio de experiências e práticas que constituem princípios da Educação Popular.

Notamos que o professor ou a professora da Educação de Jovens e Adultos, além de ampliar a sua formação, vem construindo conhecimentos e saberes por meio das experiências que foram sendo adquiridas no cotidiano da sala de aula, nas relações sociais e nos espaços formativos oferecidos pelo projeto. Esses conhecimentos constituem em um arcabouço de habilidades que o professor ou a professora utiliza, a partir das necessidades, para adequação à sua realidade.

Ao se fazer referência à modalidade EJA, identificamos a existência de uma lacuna na formação desses educadores. Mesmo possuindo experiência docente, falta-lhes a formação própria para atuar na modalidade em foco. Em decorrência disso, os espaços formativos do Projeto Sal da Terra e sua sistemática de formação e acompanhamento pedagógico têm 
procurado buscar e construir estratégias, metodologias e técnicas diferenciadas, capazes de atender às especificidades do público ao qual se destina.

Portanto, nosso estudo revelou que os processos formativos desenvolvidos no Projeto Sal da Terra têm contribuído na prática docente desses educadores que atuam na EJA e que esses espaços coletivos auxiliam na elaboração de novas metodologias e estratégias de aprendizagem. Estas são efetivadas no exercício da prática das educadoras, contemplando em seus planejamentos os saberes populares dos seus educandos e desenvolvendo com rigor teórico-técnico ações que venham fortalecer a Educação Popular.

Nesse sentido, torna-se imprescindível fomentar políticas públicas que considerem as especificidades dos sujeitos da EJA, garantindo o respeito às suas particularidades e tendo como uma de suas metas a formação de professoras para essa modalidade da educação.

\section{REFERÊNCIAS}

BARDIN, Laurence. Análise de conteúdo. Tradução Luís Antero Reto, Augusto Pinheiro. São Paulo: Edições 70, 2011.

BOGDAN, Robert; BIKLEN, Sari. Investigação qualitativa em educação. Uma introdução à teoria e aos métodos. Porto: Porto editora, 1994.

BRANDÃO, Carlos Rodrigues. O que é educação. São Paulo: Brasiliense, 2007. (Coleção primeiros passos).

BRASIL. Conselho Nacional de Educação. Resolução no 2, de $1^{0}$ de julho de 2015. Disponivel em: http://portal.mec.gov.br/seesp/arquivos/pdf/lei9394_ldbn1.pdf, Acesso em: $11 / 12 / 2020$.

BRASIL. Conselho Nacional de Educação. LDB 9394. Diretrizes e Bases da Educação Nacional. Brasília:1996. . Disponivel em:

http://portal.mec.gov.br/seesp/arquivos/pdf/lei9394 ldbn1.pdf, Acesso em: 11/12/2020.

FREIRE, Paulo. Pedagogia do oprimido. Rio de Janeiro: Paz e Terra, 1975.

FREIRE, Paulo. Pedagogia da autonomia: saberes necessários à prática educativa. 12 ed. Rio de Janeiro: Paz e Terra, 1999.

FREIRE, Paulo. Aprendendo com a própria história. 2 ed. Vol. 2. São Paulo: Paz e Terra, 2002.

FREIRE, Paulo. Pedagogia da autonomia: saberes necessários à prática educativa. 31 ed. São Paulo: Paz e Terra, 2005.

GATTI, Bernardete A. Análise das políticas públicas para formação continuada no Brasil, na última década. Revista Brasileira de Educação [online], v.13, n.37, p.57-70, 2008. 
IMBERNÓN, Francisco. Formação continuada de educadoras. Porto Alegre: Artmed, 2010.

HOLLIDAY, Oscar Jará. Ressignifiquemos as propostas e práticas de Educação Popular perante os desafios históricos contemporâneos. In: PONTUAL, Pedro; IRELAND, Timothy (Orgs.). Educação Popular na América Latina: diálogos e perspectivas. Brasília: Ministério da Educação: UNESCO, 2006.

LUDKE, Menga; ANDRÉ, Marli Eliza Dalmazo Afonso de. A. Pesquisa em Educação: Abordagens qualitativas. São Paulo: EPU, 1986.

MEJÍA, Raul Marco Jiménez. Aprofundar na Educação Popular para Construir uma Globalização desde o Sul. In: PONTUAL, Pedro; IRELAND, Timothy (Orgs.). Educação Popular na América Latina: diálogos e perspectivas. Brasília: Ministério da Educação: UNESCO, 2006.

PIMENTA, Selma Garrido (Org.). Saberes Pedagógicos e Atividade Docente. 8 ed. São Paulo: Cortez, 2012.

SILVA, Eduardo Jorge Lopes. Prática discursiva de professoras alfabetizadores de Jovens e adultos numa experiência de Educação Popular. 2011. Tese (Doutorado em Educação) Universidade Federal de Pernambuco, Recife, 2011.

TARDIF, Maurice. Saberes docentes e formação profissional. Petrópolis: Vozes, 2000. 